SURVEY OF CELSS CONCEPTS AND PRELIMINARY RESEARCH IN JAPAN

Haruhiko Ohya", Tairo Oshima** and Keiji Nitta***

- Department of Chemical Engineering, Yokohama National University, Hodogaya, Yokohama 240, Japan, "Laboratory of Chemistry for Natural Products, Tokyo Institute of Technology, Nagatsuda, Yokohama 227, Japan, ** Space Technology Research Group, National Aerospace Laboratory, Chofu, Tokyo 182, Japan

ABSTRACT

Many agricultural and other experiments relating to the development of a Controlled Ecological Life Support System (CELSS) were proposed by scientists throughout Japan in the fall of 1982. To develop concrete experimental concepts from these proposals, the engineering feasibility of each proposal was investigated by a CELSS experiment concept study group under the support of the National Aerospace Laboratory. The conclusions of the group were described in two documents, $/ 1 /, 12 \%$ Originally, the study group did not clearly define necessary missions leading to the goal of an operational CELSS for spaceflight. Therefore, the CELSS experiment concept study group met again to clarify the goals of CELSS and to determine three phases to achieve the goals. The resulting phases, or missions, and preliminary proposals and studies needed to develop a CELSS are described herein.

\title{
INTRODUCTION
}

Since 1982 a study group in Japan examined proposals for the development of a CELSS, and the problems regarding the stability of the CELSS experiment model $/ 2 /$. The general conclusions from the discussions were as follows:

1) The final targets of three necessary phases, or missions, should be more clearly defined to provide guidelines for technology development.

2) A water recycle system for urine and waste water purification should be developed to save water transportation costs.

3) A gas recycle system, containing gas separation capabilities, gas reservoirs, and pressure regulators, should be introduced to maintain air composition and pressure.

4) Waste management systems should reduce methane gas and organic sludge produced from a microbial waste management system. Therefore, incineration and wet oxidation methods are preferable to other methods as the primary waste processor for CELSS systems.

Based on these considerations and on an assessment of state of the art, three phases, or missions, are suggested, $/ 1 /, / 2 /$.

\section{THREE MISSIONS}

The most essential parts of CELSS are the systems for food production and for gas conversion from carbon dioxide to oxygen by plants and algae through photosynthesis. However, data on the morphogenesis and physiology of higher plants and algae in the space environment are not complete at the present time. Three missions are suggested to establish an operational CELSS for spaceflight.

The first mission should be conducted during 1991-1995. The purpose of this phase is to evaluate plant and algae cultivation methods and to summarize available data about the stability of photosynthesis in space. The problems of propagation in a microgravity environment is also to be studied during this phase. 
The second mission, a CELSS-dedicated mission, should be conducted during 1995-1998. The purpose of this phase is to check the feasibility of a micro closed ecology using animal and aquatic subjects instead of human beings. In this mission, non-biological waste management and recycling systems should also be tested and evaluated in the space environment.

The third mission should demonstrate the feasibility of a complete CELSS system. This phase should be conducted in a CELSS-dedicated module after 1999 and is intended to develop the future technology needed for construction of a lunar base or an advanced space station. In this mission, the main food supply and gas conversion from $\mathrm{CO}_{2}$ to $\mathrm{O}_{2}$ for one man will be based on the photosynthesis of plants and algae. Necessary animal protein could be produced by small animal and fish breeding colonies. A microbial waste management experiment, an immobilized-enzyme bio-reactor experiment, and plant cell (or tissue) cultivation experiments for future food production should also be conducted in this dedicated module. Plant species which grow well and are stable should be selected for the third mission from the results of the first and second phase missions.

\section{ARCHITECTURE OF EACH MISSION}

\section{The First Mission}

Two kinds of experimental equipment: (1) A phytotron (for plant cultivation), and (2) an algae cultivator (for algae cultivation), are essential to conduct the first phase, or mission. (Fig. 1). In addition, an artificial light supply system is needed to maintain control over light intensity and duration, and thereby control photosynthetic productivity. Other equipment such as a data management system, an enclosed work bench (a zero-gravity fume hood), a refrigerator, and a solar light supply system are required for this mission. This equipment is also required for other life science missions.

\section{Second Misston}

In this phase a closed ecological system experiment should be composed of gas and water recycling systems, in addition to the algae cultivator, and the phytotron for cultivation of higher plants.

1) In the zero-gravity field small animals, plants and algae will be used as the bio-species in the micro ecology system (Fig. 2-A). A sufficient food supply for animals may not be possible by plant cultivation. However, this experiment should require complete gas recycling between the respiration of small animals and the photosynthetic gas conversion of algae and plants. Feces and urine will be processed by the waste management and water recycling systems. Food will be supplied from outside the experimental system.

2) In an artificial gravity field produced by a rotating drum, higher plant cultivation equipment (a phytotron) should be installed for investigating the behavior of plants. (Fig. $2-B)$.

\section{The Third Mission}

To demonstrate the one-man life support capability of CELSS, a large area is required for food production by a plant cultivator. Therefore, a large-scale facility in a CELSS-dedicated module must be used for this mission.

For this demonstration (Fig. 3), a waste management system will be added with gas and water recycling systems in the environment control section of the module. The biological species section of the module will contain a large-scale plantation facility, algae cultivation equipment, and small-animal and fish vivariums. Solar light can supply the light source for photosynthesis.

The experimental and support equipment and systems for each of the three missions are listed in Table 1 . 


\begin{tabular}{|c|c|}
\hline Mission 1 & $\begin{array}{l}\text { Phytotron } \\
\text { Algae Cultivator } \\
\text { Data Management System } \\
\quad \text { (including TV/VTR Equipment) } \\
\text { Artificial Light Supply System }\end{array}$ \\
\hline Mission 2 & $\begin{array}{l}\text { Phytotron } \\
\text { Algae Cultivator } \\
\text { Fish Breeding Equipment } \\
\text { Small Animal Vivarium } \\
\text { Rotating. Drum } \\
\text { Data Management System } \\
\quad \text { (including TV/VTR Equipment) } \\
\text { Solar Light Supoly System (possibly) } \\
\text { Waste Management System } \\
\text { Water Recycle System } \\
\text { Gas Recycle System } \\
\text { Enclosed Work Bench } \\
\text { Refrigerator }\end{array}$ \\
\hline Mission 3 & $\begin{array}{l}\text { Large Scale Rotating Plantation Facility } \\
\text { Callus Cultivator } \\
\text { Algae Cultivator } \\
\text { Fish Breeding Equipment } \\
\text { Small Animal Vivarium } \\
\text { Human Subject } \\
\text { Rotating Drum } \\
\text { Data Management System } \\
\text { (including TV/VTR Equipment) } \\
\text { Solar Light Supply System (possibly) } \\
\text { Waste Management System } \\
\text { Water Recycle System } \\
\text { Gas Recycle System } \\
\text { Microbial Waste Management Equipment } \\
\text { Immobilized Enzyme Bioreactor } \\
\text { Galley } \\
\text { Shower } \\
\text { Toilet }\end{array}$ \\
\hline
\end{tabular}

PRELIMINARY DESIGN WORK AND SYSTEM INTEGRATION FOR EACH MISSION

The requirements for experimental devices and systems were deduced by the CELSS concept study group considering the developmental steps of CELSS technology and the need to limit initial development costs. Based on these requirements, systems were designed by four manufacturers: Hitachi Ltd., Mitsubishi Electric Ltd., Kawasaki Heavy Industry, and Mitsubishi Heavy Industry. These companies were asked to determine the measuring instruments required on the mission, and to estimate the weight, size, shape and electric power requirements for each experimental device or system.

The experimental equipment should be installed and integrated in the experimental module as easily as possible. Therefore the location of each device must be determined with the following considerations in mind:

1) Experimental procedures

2) Functions of each device

3) Weight of each device 
4) Power consumption

5) Size of each device.

An example of equipment integration in a typical Spacelab or space station module is shown in Fig. 4.

PROPOSALS AND PRELIMINARY STUDIES MADE BY INDIVIDUAL RESEARCH GROUPS

The following is a summary of CELSS-related studies in Japan.

1) An example of a biological recycling system is shown in Fig. 5. This system, proposed by Prof. Yatazawa of Nagoya University, consists of various living organisms and a number of biological subsystems $(\mathrm{S} / \mathrm{S})$. Attention should be paid to the inclusion of the following:

a) Biological nitrogen fixation by Azolla-Anabaena symbiosis (S/S 2)

b) Sodium extraction by edible halophytes, plants native to salt marshes or alkaline soils (S/S 5)

c) Cellulolytic food production by mushroom fungi (S/S 4$)$.

2) Dr. I. Endo of the Chemical Engineering Laboratory, Institute for Physical and Chemical Research, has proposed the use of algae (Spirulina sp.) for the production of oxygen and foods. Dr. Endo and his collaborators have carefully considered zero gravity and other environmental conditions in the space station. His system includes many experimental and measuring devices requiring very few operators for control. Computer hardware and software has been developed for monitoring cultivation of Spirulina sp. A computer model has calculated the size of a fermentor, the volume of the gas reservoir, the size of the tank for the medium, the size of the waste water tank, methods for cultivation, light supply characteristics, fermentor agitation, separation methods for algae, methods of oxygen removal, and the characteristics of automatic monitoring and control of the system. One of the most difficult problems is contamination by bacteria in a space environment. These studies are continuing with the collaboration of the Institute of Physical and Chemical Research and the National Aerospace Laboratory.

3) To study the suitability of various crop species and their nutrient balance, scientists affiliated with Japan's Ministry of Agriculture and the Departments of Forestry and Fisheries have investigated a wide range of crop species for nutrition and ease of planting in space. As an example, the relative advantages of growing the sweet potato in space follows.

The sweet potato provides a lower moisture content and greater food energy than the white potato. Two $\mathrm{kg}$ of sweet potato supplies $2400 \mathrm{Kcal}$; various nutrients such as $24 \mathrm{~g}$ protein, $4 \mathrm{~g}$ fat, $600 \mathrm{mg}$ calcium, $10 \mathrm{mg}$ iron, $0.2 \mathrm{mg}$ carotine, $2 \mathrm{mg}$ Vitamin B1, $1 \mathrm{mg}$ Vitamin $\mathrm{B} 2,600 \mathrm{mg}$ Vitamin $\mathrm{C}$, and about $1400 \mathrm{~g}$ of water. Although protein, fat and carotine vary with species variety and cultivation methods, it may be possible, through selective breeding in space, to increase the nutritive value of the crop.

The sweet potato also has the advantage of having edible leaves and vines, as well as the tuber. If a variety of sweet potato with good cultivation characteristics under the weightlessness of low gravity can be selected, it may well become the "First Crop in Space."

4) As a possible life support system in space, a biochemical oxygen and carbon recycling apparatus has been proposed by Prof. T. Oshima of Tokyo Institute of Technlogy. This apparatus is intended to replace living plants or algae. The first unit in the bioreactor is for photoreaction and oxygen generation. It is composed of a chloroplast suspension (a film of immobilized chloroplast particles), used to produce molecular oxygen, ATP and NADPH under sunlight. The second unit is composed of Immobilized enzymes, or possibly whole cells which fix $\mathrm{CO}_{2}$ into organic compounds using the supply of ATP and NADPH from the first unit. The advantages of the bioreactor system over living organisms are:

a) Bioreactors are easier to control and more stable than living organisms

b) Weightlessness may not seriously affect the reactors.

In cooperation with Mitsubishi Electric Company (Drs. S. Isoda and M. Maeda), a model experiment is being designed for space station. Fig. 6 shows a rough sketch of the bioreactor system. 
Production of oxygen and reduced compound(s), especially molecular hydrogen, from chloroplast particles has been studied by many researchers, Therefore Dr. Oshima and his colleagues have focused their attention on the second reactor in the system. Based on stabilized enzyme systems from thermophilic algae (Synechococcus lividus), isolated from a hot spring and grown at $55^{\circ} \mathrm{C}$, is immobilized in an agarose matrix and then treated at cold temperatures to damage the cell envelopes. The immobilized cells are incubated in the presence of ATP, NADPH and carbonate ion. Theoretically, glucose will be produced from 18 ATP and 12 NADPH according to the following formula:

$$
6 \mathrm{CO}_{2}+18 \mathrm{NADPH}+12 \mathrm{H}_{2} \mathrm{O} \rightarrow \mathrm{C}_{6} \mathrm{H}_{12} \mathrm{O}_{6}+18 \mathrm{P}_{1}+12 \mathrm{NADPH}+6 \mathrm{H}^{+}
$$

Hydrogen bacteria, especially a thermophilic strain, is also considered as an enzyme source for the-second unit. A preliminary design for this bioreactor is shown in Fig. 7 .

REFERENCES

1. Mission Model Study for Space Station. MSS-SS-01. Report -- Japan Space Station Task Force, National Aerospace Lab., Tokyo, Japan, 1981.

2. Preliminary Concepts of Space Station Missions. MS-SS-02. Report -- CELSS Experiment Concept Study Group, National Aerospace Lab., Tokyo, Japan. 1981.

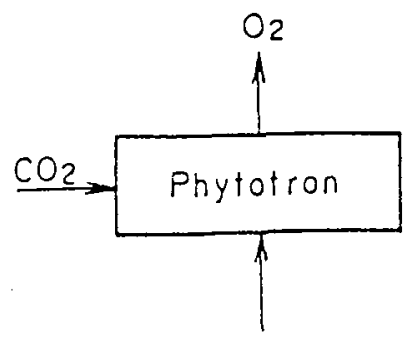

Nutrient

Solution

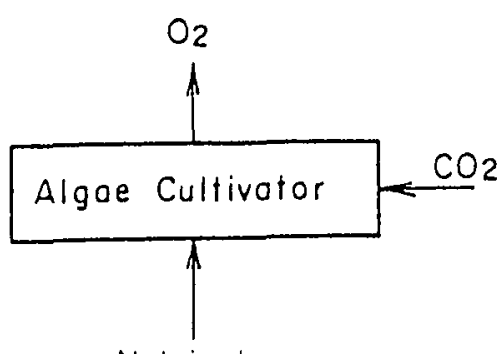

Nutrient

Solution

Fig.1. First phase experimental concept
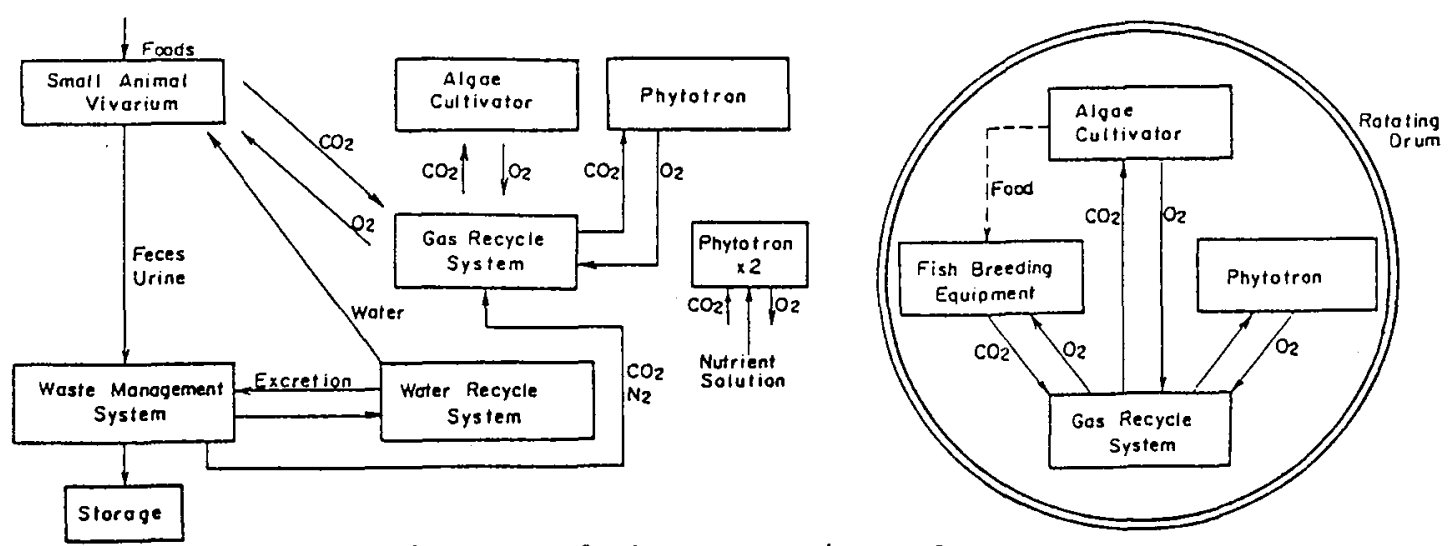

Fig.2. Second phase experimental concept 


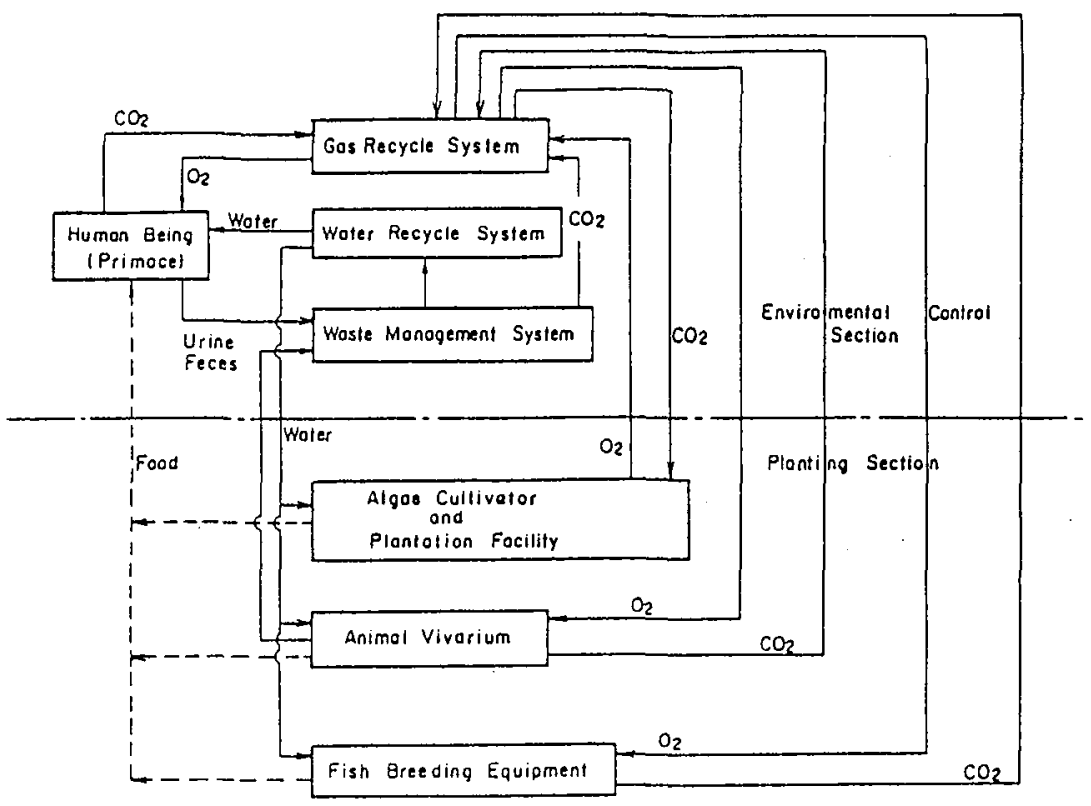

Fig.3. Third phase experimental concept

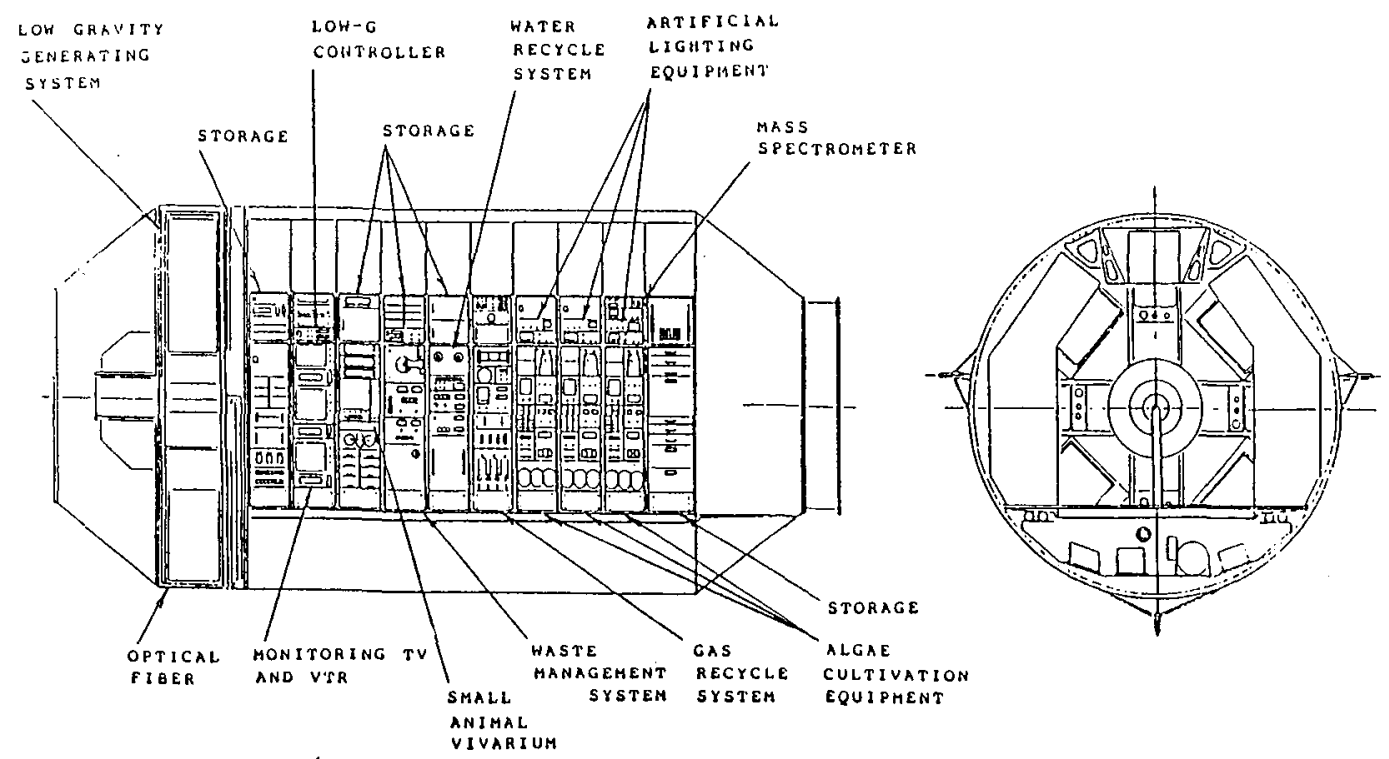

Fig.4. The second time phase mission experiment integration 

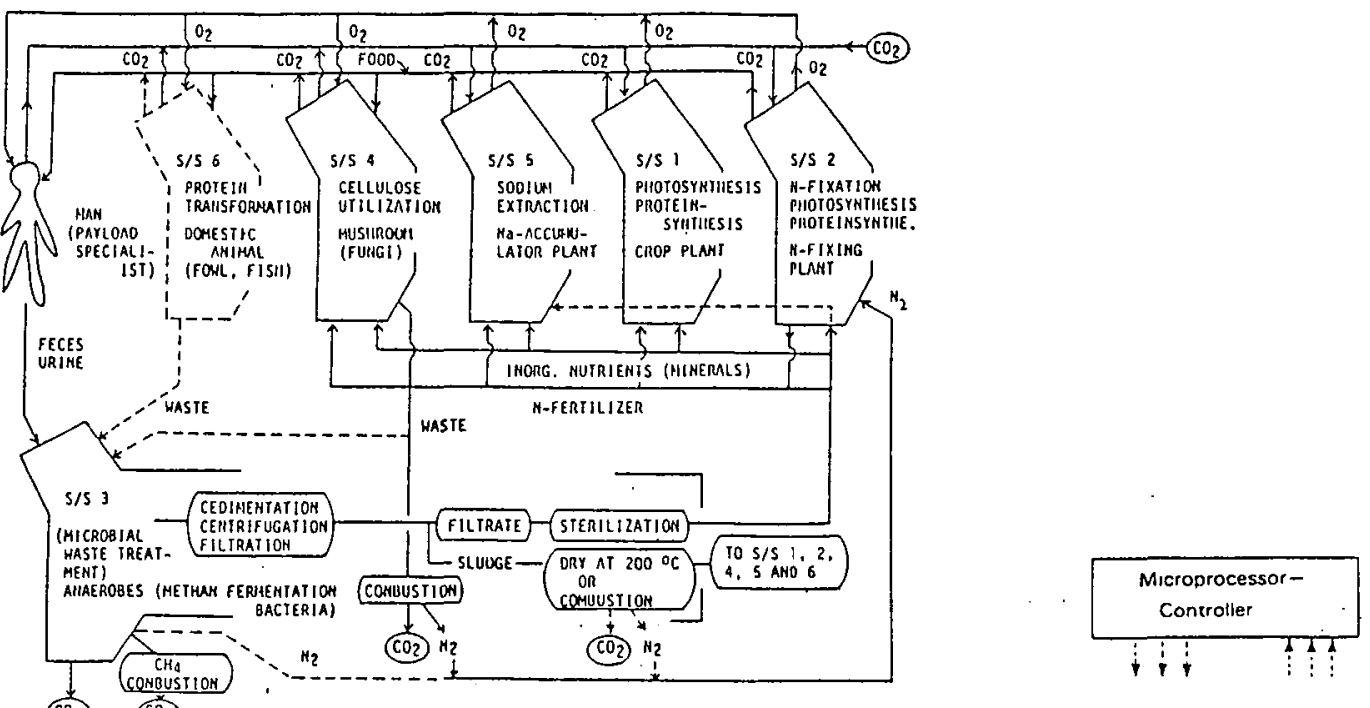

(102) (CO2)

Fig.5. Proposed scheme of controlled ecological life support system

Fig.6. Schematic diagram of a bioreactor system using immobilized enzymes

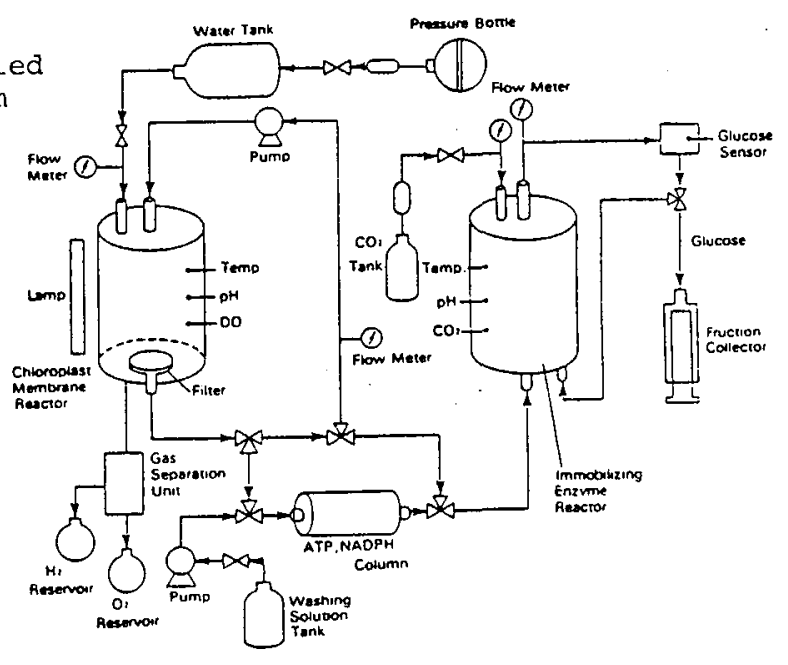

Enzyme Immobilzing Bioreoctor Equipment

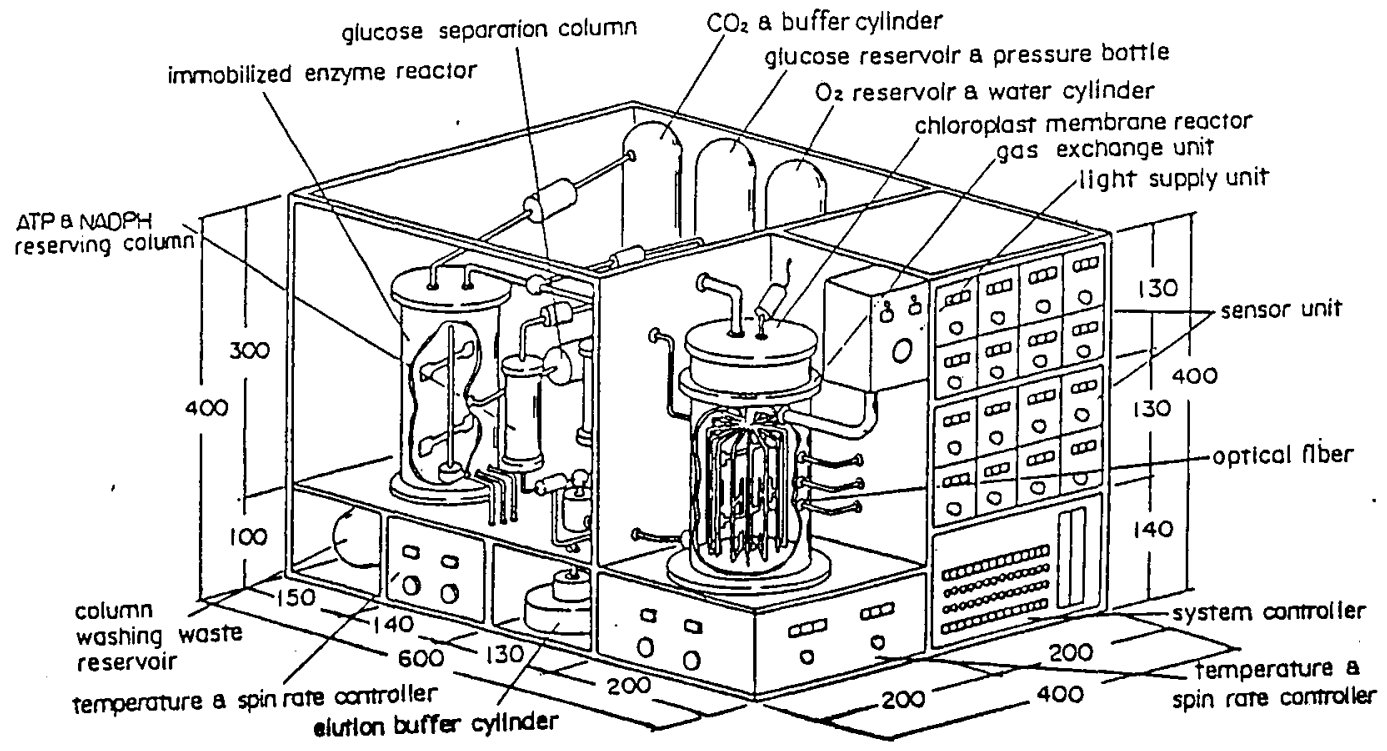

Fig. 7. A proposed design for the bioreactor experiment using imobilized enzymes. 